\title{
Framework de avaliação da complexidade de projetos em portfólios de engenharia civil
}

\author{
A framework for evaluating the complexity of projects in \\ civil engineering portfolios
}
Alessandro Prudêncio Lukosevicius
Carlos Alberto Pereira Soares
Luiz Antônio Joia

Resumo

A

importância da complexidade para o desempenho dos negócios tem ganhado reconhecimento acadêmico e gerencial. Saber lidar de forma efetiva com a complexidade é um diferencial para as

organizações, incluindo as temporárias (projetos). Portanto, um melhor entendimento da complexidade em projetos e suas aplicações mostra-se necessário. No entanto, a literatura científica é carente de frameworks para avaliar a complexidade nas organizações, especialmente na área de construção civil. Assim, o objetivo deste artigo exploratório é propor um framework para avaliar a complexidade de projetos em portfólios de engenharia civil. O framework foi criado a partir dos fatores de complexidade em projetos de engenharia identificados pela revisão bibliográfica, tratado pela técnica para tomada de decisão ANP (Analytic Network Process) e suportado pela Teoria da Complexidade. Como resultado, foi criado o MID (multiplicidade, interdependência, diversidade) Framework e aplicado em um exemplo para priorizar o portfólio de projetos de uma empresa de construção civil. Em relação ao TOE (technical, organizational and environmental) Framework adotado pela literatura, a pesquisa sugere que o MID Framework é mais amplo (avalia qualquer tipo de projeto), mais simples (estrutura mais enxuta) e mais diversificado (calcula as complexidades do projeto e do projeto no portfólio) para priorização de portfólios na área de engenharia civil.

Palavras-chave: Projetos complexos. Teoria da complexidade. Analytic Network Process (ANP). Gerenciamento de portfólio. Métodos de tomada de decisão.

Abstract

The importance of complexity to business performance has gained academic and managerial recognition. Knowing how to deal effectively with complexity is a differential for organizations, including temporary ones (projects). Therefore, a better understanding of the complexity of projects and their applications is necessary. However, the scientific literature shows a lack of frameworks to assess complexity in organisations, especially in the field of civil construction. Thus, the

Alessandra Prudência Lukosevicius Universidade Federal Fluminense Niterói - RJ - Brasil

Carlos Alberto Soares Universidade Federal Fluminense Niterói - RJ - Brasil

Luiz Antônio Joia Fundação Getulio Vargas Rio de Janeiro - RJ - Brasil

Recebido em 27/04/16 Aceito em 07/01/17

objective of this exploratory article is to propose a framework to evaluate the complexity of projects in civil engineering portfolios. The framework was created from the complexity factors in engineering projects identified by a bibliographic review, dealt with by the Analytic Network Process (ANP) decision making technique and supported by the Complexity Theory. As a result, the Multiplicity, Interdependence, Diversity (MID) framework was created and used in an example to prioritize the project portfolio of a construction company. In terms of the Technical, Organizational and Environmental (TOE) framework, the research suggests that the MID Framework is broader (evaluates any type of project), simpler (leaner structure), and more diverse (calculates the complexities of the project and the project in the portfolio) to prioritize portfolios in the area of civil engineering.

Keywords: Complex projects. Complexity theory. Analytic Network Process (ANP). Portfolio management. Decision making methods.
\end{abstract}

LUKOSEVICIUS, A. P.; SOARES, C. A. P.; JOIA, L. A. Framework de avaliação da complexidade de projetos em portfólios 323 de engenharia civil. Ambiente Construído, Porto Alegre, v. 17, n. 4, p. 323-342, out./dez. 2017. ISSN 1678-8621 Associação Nacional de Tecnologia do Ambiente Construído. http://dx.doi.org/10.1590/s1678-86212017000400200 


\section{Introdução}

$\mathrm{Na}$ literatura científica há a percepção de que a complexidade em geral (SAYNISCH, 2010; SHEFFIELD; SANKARAN; HASLETT, 2012) e, em particular, nos projetos (BACCARINI, 1996; VIDAL; MARLE; BOCQUET, 2011) está aumentando. Por exemplo, no mundo corporativo o principal desafio dos CEOs tem sido a complexidade de operar em um ambiente cada vez mais volátil e incerto (PROJECT..., 2013).

O comportamento das economias e mercados, as mudanças na sociedade, o ritmo das inovações e a emergência de novas tecnologias são exemplos de fatores que contribuem para o aumento da complexidade nos tempos modernos (PROJECT..., 2014). Portanto, um melhor entendimento das características e conceitos de complexidade em um projeto mostra-se útil e desejável.

Para o Project... (2013), lidar efetivamente com a complexidade proporciona uma vantagem competitiva. Por exemplo, a universidade de Pretória realizou um estudo, em 2011, com empresas sul-africanas do setor de tecnologia da informação sobre a relação entre complexidade e lucratividade. $\mathrm{O}$ estudo constatou que existe alta correlação positiva (98\%) entre as duas variáveis, o que mostra a importância da complexidade para a robustez dos negócios (CLARENS, 2011).

$\mathrm{Na}$ engenharia civil, campo marcado por empreendimentos de diversos portes, a história é a mesma, pois, apesar de a complexidade em projetos ser considerada emergente nesse campo, ela é crítica para o gerenciamento de projetos de construção (LU et al., 2015; HE et al., 2015). Afinal, diversos pesquisadores têm reconhecido a importância da complexidade, principalmente em projetos de construção de grande escala (WIENDAHL; SCHOLTISSEK, 1994; BACARINI, 1996; LITTLE, 1997).

Assim, o entendimento da complexidade está sendo reconhecido como fator-chave para melhorar o desempenho do gerenciamento de projetos (ARITUA; SMITH; BOWER, 2009), elevando a importância do tema para acadêmicos e praticantes.

Do ponto de vista acadêmico, a relevância do tema é dada pelo fato de o gerenciamento de projetos constantemente receber críticas a respeito de sua baixa robustez teórica e empírica. Nesse sentido, o estudo da complexidade em projetos pode aumentar a consistência das pesquisas em gerenciamento de projetos (SODERLUND, 2003; PROJECT..., 2009).

Essa abordagem pode abrir novas fronteiras de estudo porque enriquece e expande o paradigma cartesiano atual, contemplando os projetos complexos (COOKIE-DAVIS et al., 2007). Recentemente, o grande número de artigos relacionados a complexidade demonstra que o tema ganha força no campo de pesquisas em gerenciamento de projetos (BOSCH-REKVELDT et al., 2011).

Do ponto de vista prático, o tema é importante, pois a complexidade, para ser gerenciada, deve ser quantificada de alguma maneira (RENSBURG, 2012). Essa medição pode auxiliar no direcionamento de recursos e definição de objetivos organizacionais. Além disso, a não linearidade e sua influência no modo de planejar e gerenciar projetos devem ser foco de atenção dos respectivos gerentes de projetos (SINGH; SINGH, 2002).

Outros autores, como Winter et al. (2006), destacam a necessidade de desenvolver novas ontologias e epistemologias para iluminar e ampliar o entendimento da complexidade em projetos, visando enriquecer as práticas atuais de gerenciamento. Nessa direção, a complexidade em projetos deve ser medida para melhor atender ao gerenciamento moderno de projetos (VIDAL; MARLE; BOCQUET, 2011).

$\mathrm{O}$ entendimento e medição da complexidade visa obter ideias sobre a complexidade do sistema para formular estratégias que façam o sistema como um todo prosperar (RENSBURG, 2012). Considerando os projetos como sistemas, essa medição poderia ser avaliada por meio de uma escala, pois todos os projetos possuem algum grau de complexidade (WHITTY; MAYLOR, 2009). Dessa forma, a complexidade é relativa, pois os padrões que as pessoas utilizam para julgá-la dependem das experiências pessoais e coletivas de cada um (KURTZ; SNOWDEN, 2003).

Em termos semânticos, na literatura científica a complexidade aplicada ao campo de gerenciamento de projetos ora é tratada pela expressão "projetos complexos", ora pela expressão "complexidade em projetos". Para fins desta pesquisa, ambas as expressões serão aceitas e diretamente ligadas ao estudo da complexidade de um projeto.

Em relação à complexidade dos projetos, os estudos têm focalizado no nível de evolução, não linearidade, emergência e imprevisibilidade das interações entre os participantes dos projetos (atores humanos e não humanos) (PROJECT..., 2009). Isso porque, pela Teoria da Complexidade, projetos são sistemas adaptativos complexos que exigem gerenciamento (WILLIAMS, 1999; WHITTY; MAYLOR, 2009). Em um sistema complexo os diferentes elementos interagem e produzem saídas 
que são imprevisíveis e não lineares (MAYLOR; VIDGEN; CARVER, 2008). Por isso, sistemas complexos não podem ter o comportamento inferido a partir de seus componentes (WHITTY; MAYLOR, 2009).

Esses conceitos podem ter profundas implicações no paradigma atual de gerenciamento de projetos, principalmente nos projetos de construção, trazendo uma forma complementar de pensar os fenômenos nessa área e abrindo possibilidades para a aplicação de novos conhecimentos, práticas, ferramentas e técnicas. Assim, para lidar com a complexidade, é necessário descobrir novos meios de gerenciá-la.

Mas como medir a complexidade de um projeto? Questionamentos como esse mostram que existe uma busca por frameworks de avaliação da complexidade que possam ser utilizados de forma sistêmica (MOREL; RAMANUJAM, 1999; XIA; LEE, 2004; MAYLOR; VIDGEN; CARVER, 2008; BOSCH-REKVELDT et al., 2011; GERALDI; MAYLOR; WILLIAMS, 2011; VIDAL; MARLE; BOCQUET, 2011), e a área de construção civil não é exceção.

Esse hiato na literatura mostra a relevância de se estudar a percepção dos profissionais de gerenciamento de projetos em relação à complexidade em projetos, assim como o estabelecimento de um framework para medi-la.

Um framework pode ser entendido como um método, isto é, um conjunto de passos para se executar uma tarefa. March e Smith (1995, p. 257) esclarecem que "[...] métodos baseiam-se em um conjunto de constructos subjacentes (linguagem) e uma representação (modelo) em um espaço de solução [...]". Os autores ainda explicam que os métodos podem ter modelos como entrada que submetidos a uma sequência de passos levam à solução de um problema. $\mathrm{O}$ framework criado a partir dos fatores de complexidade em projetos de engenharia (LUKOSEVICIUS, 2015) apoia-se em pesquisa exploratória da literatura científica, tratamento pela técnica para tomada de decisão ANP (Analytic Network Process) e suporte pela Teoria da Complexidade.

Em face dos elementos colocados, este trabalho visa propor um framework para avaliar a complexidade de projetos em portfólios de engenharia civil. Desse modo, os gestores de portfólio de projetos na área de engenharia civil podem aplicar o MID (multiplicidade, interdependência, diversidade) Framework, método proposto neste trabalho, para avaliar a complexidade de seus projetos e, assim, priorizar seus portfólios e investimentos de acordo com o critério complexidade.

\section{Complexidade em projetos de engenharia civil}

A indústria da construção civil é bastante relevante para o desenvolvimento econômico e social do Brasil (BANCO..., 2010), pois consome grandes volumes de bens e serviços de outros setores, além de absorver muita mão de obra não especializada. Ademais, esse setor envolve uma cadeia produtiva marcada pela diversidade de partes interessadas (SOUZA et al., 2004), tipologia de empresas, tecnologias, qualificação de pessoal e atuação geográfica.

Consequentemente, a cadeia da construção abarca tanto indústrias de tecnologia de ponta e capital intensivo, quanto setores industriais diversos, tais como siderurgia, mineração, metalurgia, prestadores de serviços, além de ramos produtores de fios e cabos, equipamentos elétricos e mecânicos, vidro, cerâmica, madeira e plásticos (DEPARTAMENTO..., 2008). Todavia, a indústria da construção civil investe pouco em pesquisa e desenvolvimento (P\&D) (FOSSATI; ROMAN, 2006), sendo esse um dos gargalos para a evolução dessa área na busca por um caráter mais industrial (MELHADO, 2001). Aliado a isso, esse setor possui um histórico de baixa velocidade de difusão de novos recursos tecnológicos, o que atrasa a absorção de inovações tecnológicas (MARTINS; BARROS, 2003).

No entanto, deve-se reconhecer que essa área é atípica, pois existe uma dependência recíproca entre o produto e o processo produtivo (SOUTO, 2003; CENTRO..., 2009). No entanto, em muitos casos o design do produto em construção é concebido em uma etapa estanque e desvinculada em termos de gestão das etapas posteriores de construção do empreendimento. Além disso, o produto de um projeto de construção é heterogêneo, não seriado e dependente de encomendas.

Por essas razões, é natural que um projeto de construção traga um grau considerável de incerteza, elemento que está na essência da ideia de complexidade, conforme relatam os estudos prévios sobre avaliação da complexidade em projetos de construção (Quadro 1). Essa incerteza ocorre principalmente quando se desenvolvem projetos de grande porte com muitos atores envolvidos (VELDE; DONK, 2002). 
Afinal, um projeto de construção é definido como,

[...] uma organização para converter uma ideia ou desenho de engenharia ou trabalho de construção com vias a preencher as necessidades humanas ou econômicas dentro dos limites de qualidade, custo e duração [...] (SANTANA, 1990, p. 102).

Por exemplo, a crescente demanda por obras de infraestrutura, fruto de parcerias público-privadas, geralmente conduzidas com cronogramas e orçamentos apertados, tem gerado importantes desafios para a gestão de obras públicas (MARREWIJK et al., 2008), como a criação de novas formas de contratação e gestão dos projetos que evitem os aumentos de custo e prazo dessas obras (IYER; CHAPHALKAR; JOSHI, 2008).
Os elementos relatados anteriormente parecem apontar para a necessidade do entendimento da complexidade em projetos para um melhor gerenciamento deles. Dessa forma, no gerenciamento de projetos de construção, a complexidade continua a atrair considerável pesquisa e reavaliação, exigindo o entendimento de como a complexidade do projeto pode impactar em cascata os processos de construção (COOKE, 2013). Por exemplo, a avaliação do nível de complexidade pode permitir aos tomadores de decisão e clientes o compartilhamento de informações. Esse compartilhamento pode ajudar a desenvolver estratégias apropriadas para a execução dos projetos (HE et al., 2015), e assim melhorar o gerenciamento de riscos, pessoas e metas (XIA; CHAN, 2012).

\section{Quadro 1 - Estudos prévios sobre avaliação da complexidade em projetos de construção}

\begin{tabular}{|c|c|}
\hline Autores & $\begin{array}{l}\text { Resultados } \\
\end{array}$ \\
\hline Gidado (1996) & $\begin{array}{l}\text { Propuseram uma abordagem para avaliar a complexidade do } \\
\text { processo de produção na construção }\end{array}$ \\
\hline Sinha, Kumar e Thomson (2006) & $\begin{array}{l}\text { Descreveram um framework para avaliar a complexidade de um } \\
\text { projeto e sugeriram um índice de complexidade (IC) }\end{array}$ \\
\hline Maylor, Vidgen e Carver (2008) & Reportaram um modelo para o gerenciamento da complexidade \\
\hline Vidal e Marle (2008) & $\begin{array}{l}\text { Desenvolveram o modelo de complexidade para projetos } \\
\text { denominado ALOE (attributes, links, objects, events) }\end{array}$ \\
\hline Remington, Zolin e Turner (2009) & $\begin{array}{l}\text { Revelaram um vasto grupo de fatores de complexidade em } \\
\text { projetos }\end{array}$ \\
\hline $\begin{array}{l}\text { Geraldi, Maylor e Williams } \\
\text { (2011) }\end{array}$ & $\begin{array}{l}\text { Sumarizaram os frameworks de complexidade em projetos por } \\
\text { meio de revisão sistemática de literatura }\end{array}$ \\
\hline Wood e Ashton (2010) & $\begin{array}{l}\text { Desenvolveram um modelo para avaliar a complexidade nos } \\
\text { estágios iniciais usando métodos mistos }\end{array}$ \\
\hline $\begin{array}{l}\text { Vidal, Marle e Bocquet (2010, } \\
\text { 2011) }\end{array}$ & $\begin{array}{l}\text { Utilizaram a analytic hierarchy process (AHP) e formularam um } \\
\text { modelo de avaliação da complexidade em projetos para assistir } \\
\text { nas decisões dos gerentes de projetos }\end{array}$ \\
\hline Bosch-Rekveldt et al. (2011) & $\begin{array}{l}\text { Elaboraram o TOE (Technical, Organizational and } \\
\text { Environmental) Framework para avaliar a complexidade em } \\
\text { grandes projetos de engenharia }\end{array}$ \\
\hline Lebcir e Choudrie (2011) & $\begin{array}{l}\text { Desenvolveram um framework para complexidade em projetos de } \\
\text { construção }\end{array}$ \\
\hline Giezen (2012) & $\begin{array}{l}\text { Analisaram as vantagens e desvantagens da redução da } \\
\text { complexidade no planejamento de megaprojetos }\end{array}$ \\
\hline Gransberg et al. (2012) & $\begin{array}{l}\text { Desenvolveram as “pistas de complexidade” para projetos } \\
\text { complexos }\end{array}$ \\
\hline Owens et al. (2012) & $\begin{array}{l}\text { Desenvolveram um modelo de cinco dimensões que adiciona } \\
\text { contexto e finanças }\end{array}$ \\
\hline Shafiei-Monfared e Jenab (2012) & $\begin{array}{l}\text { Avaliaram a complexidade relativa de projetos de design usando } \\
\text { gráficos gerenciais e técnicos, e matriz de complexidade } \\
\text { estrutural de design (CDSM) }\end{array}$ \\
\hline Xia e Chan (2012) & $\begin{array}{l}\text { Avaliaram o grau de complexidade de projetos de edifícios e } \\
\text { desenvolveram um índice de complexidade (IC) usando o método } \\
\text { Delphi }\end{array}$ \\
\hline Lessard, Sakhrani e Miller (2013) & $\begin{array}{l}\text { Elaboraram um trabalho para entender a complexidade em } \\
\text { grandes projetos de infraestrutura }\end{array}$ \\
\hline
\end{tabular}

Fonte: Lu et al. (2015). 
Nessa direção, embora não exista um entendimento unificado sobre complexidade na comunidade de gerenciamento de projetos (VIDAL; MARLE, 2008), alguns autores apresentam conceituações e entendimentos sobre o tema:

(a) a complexidade em projetos é o número de diferentes disciplinas ou departamentos envolvidos no projeto, assim como a complicação do design propriamente dito (LARSON; GOBELLI, 1989);

(b) consiste de muitas, variadas e interrelacionadas partes e pode ser operacionalizada em termos de diferenciação e interdependência (BACCARINI, 1996);

(c) é uma evolução gerada por princípios físicos e regras matemáticas simples, que mostram comportamentos complicados e não previsíveis (DIJKUM, 1997);

(d) é caracterizada pelo número de elementos e suas interdependências, incluindo múltiplos objetivos e multiplicidade de stakeholders, assim como a incerteza dos métodos e metas (WILLIAMS, 1999);

(e) é a medida da dificuldade inerente para entender um sistema complexo, assim como a quantidade de informações necessárias para entendê-lo (BAR-YAM, 2003);

(f) pode ser melhor descrita pelo número de estados que um sistema pode ter de acordo com os drives variedade, interdependência, ambiguidade e fluxo (NEDOPIL; STEGER; AMANN, 2011);

(g) é a propriedade de um projeto que o torna difícil de entender, prever e manter seu comportamento geral sob controle, mesmo que existam informações razoavelmente completas sobre o sistema do projeto (VIDAL; MARLE; BOCQUET, 2011); e

(h) é a característica do programa, projeto ou seus ambientes que torna difícil seu gerenciamento (PROJECT..., 2014). Para os autores deste artigo, a complexidade de um projeto se estrutura e pode ser avaliada tendo como referência a multiplicidade, interdependência e diversidade dos elementos internos e externos ao ambiente do projeto, conforme Lukosevicius (2015).

\section{Método de pesquisa}

Os três momentos da pesquisa foram (Figura 1):

(a) pesquisa exploratória para criar o Framework;

(b) teste do Framework em um exemplo; e

(c) discussão do Framework.

A pesquisa exploratória permite ao pesquisador conhecer melhor o problema de pesquisa, sendo objetivo tornar o problema mais explícito e construir hipóteses (GIL, 2010). Assim, neste estudo o primeiro momento consistiu em explorar a literatura científica para conhecer melhor o problema, identificar os fatores que influenciem a complexidade e propor um novo framework para sua avaliação.

Nesse momento, a coleta de dados baseou-se em fontes de material já publicado oriundos de fontes bibliográficas, como artigos, livros, revistas, jornais, dissertações e teses, e as disponibilizadas eletronicamente por meio da internet, principalmente as fontes do portal de periódicos da Coordenação de Aperfeiçoamento de Pessoal de Nível Superior (Capes). Gil (2010) destaca que a vantagem dessa estratégia de coleta de dados é permitir ao pesquisador cobrir um leque de fenômenos mais amplo do que aquele que ele poderia pesquisar diretamente.

Como resultado da pesquisa exploratória, adotaram-se os dados secundários propostos por Lukosevicius (2015), por serem aplicados a qualquer dimensão de projeto na área de engenharia civil. Esse autor empreendeu um estudo para identificar os fatores representantes do objeto "projeto complexo" na percepção de 132 profissionais de gerenciamento de projetos da área de engenharia, capturados por meio da técnica de evocação de palavras, tratada e analisada pela técnica de Vèrges com o apoio das Teorias da Representação Social e da Complexidade. Os fatores identificados foram stakeholders, dificuldade, riscos, tecnologia, grande, escopo, multidisciplinar e longo.

Figura 1 - Momentos da pesquisa

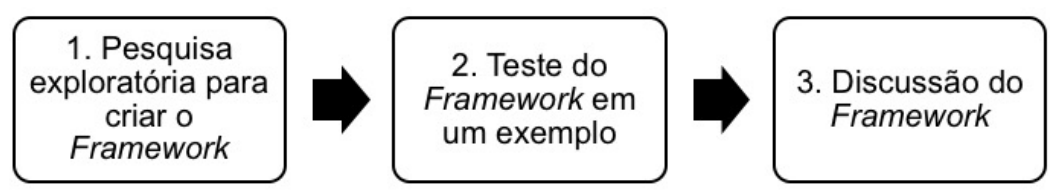


Neste ponto vale esclarecer que a técnica de evocação de palavras permite capturar a percepção dos respondentes a respeito de um objeto. Essa técnica solicita ao respondente que informe os primeiros pensamentos que lhe vêm à cabeça quando lê ou ouve uma expressão indutora. Depois de evocadas, as palavras são organizadas por meio da técnica de Vèrges em um gráfico com quatro divisões, denominadas os quatro quadrantes de Vèrges.

Em seguida, os fatores identificados por Lukosevicius (2015) foram comparados com os fatores propostos por um método de complexidade desenvolvido para a área de engenharia denominado TOE (Technical, Organizational $e$ Environmental) Framework. Essa comparação permitiu melhor robustez e segurança na categorização dos fatores, uma vez que o TOE Framework já é utilizado na área de engenharia.

O TOE Framework foi proposto por BoschRekveldt et al. (2011) e é composto de 50 fatores divididos em 3 grupos e 14 subgrupos (Figura 2). O grupo complexidade técnica engloba os subgrupos metas, escopo, experiência, atividades e risco, e contém 15 fatores. O grupo complexidade organizacional engloba as subgrupos tamanho, recursos, equipe do projeto, confiança e risco, e contém 21 fatores. Por fim, o grupo complexidade ambiental engloba as subgrupos stakeholders, localização, condições de mercado e risco, e contém 14 fatores. Dessa forma, após as comparações, estruturaram-se os grupos (clusters) e os fatores do Framework.
Para o momento 2 o framework foi testado de acordo com os passos preconizados pela ANP (Analytic Network Process) para priorizar o portfólio de projetos de engenharia de uma empresa de construção civil. A ANP (Analytic Network Process) é uma técnica de apoio à tomada de decisão com múltiplos critérios que considera a dependência (ou influência) e feedback entre os grupos e/ou fatores de decisão. A ANP tem sido empregada em vários campos do conhecimento, como meio ambiente (BOTTERO; COMINO; RIGGIO, 2011; POUREBRAHIM et al., 2010) e estratégia (ASAN; SOYER, 2009).

A técnica ANP foi utilizada para criar e aplicar o framework de avaliação da complexidade. A Figura 3 ilustra o passo a passo da técnica ANP em três estágios:
(a) criar o modelo;
(b) julgar os grupos e fatores; $\mathrm{e}$
(c) calcular as prioridades.

O estágio 1 refere-se à criação do modelo, e os estágios 2 e 3 referem-se a sua aplicação.

No estágio 1 criou-se o modelo por meio do desenho da rede, estabeleceram-se os grupos e fatores, e determinaram-se as relações de dependência e feedback, que podem ser: grupo com grupo (outer dependence), grupo com elemento (feedback) e elemento com elemento (inner dependence).

Figura 2 - Grupos e subgrupos do TOE Framework

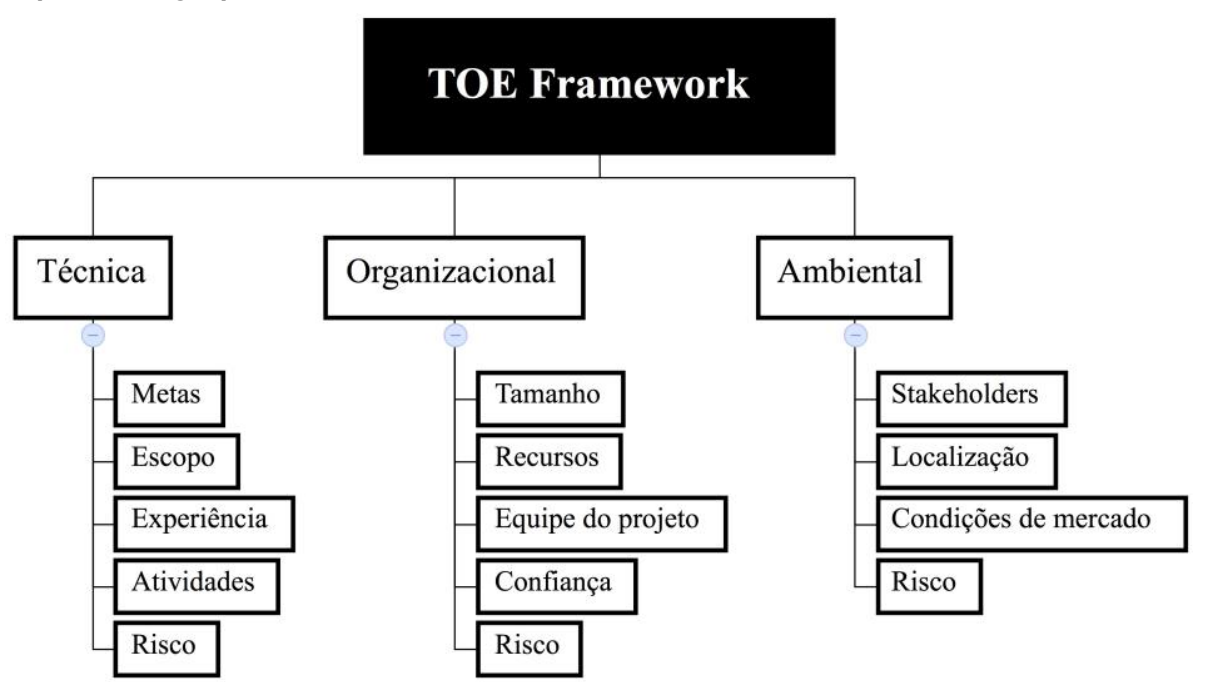


Figura 3 - Passos da técnica ANP

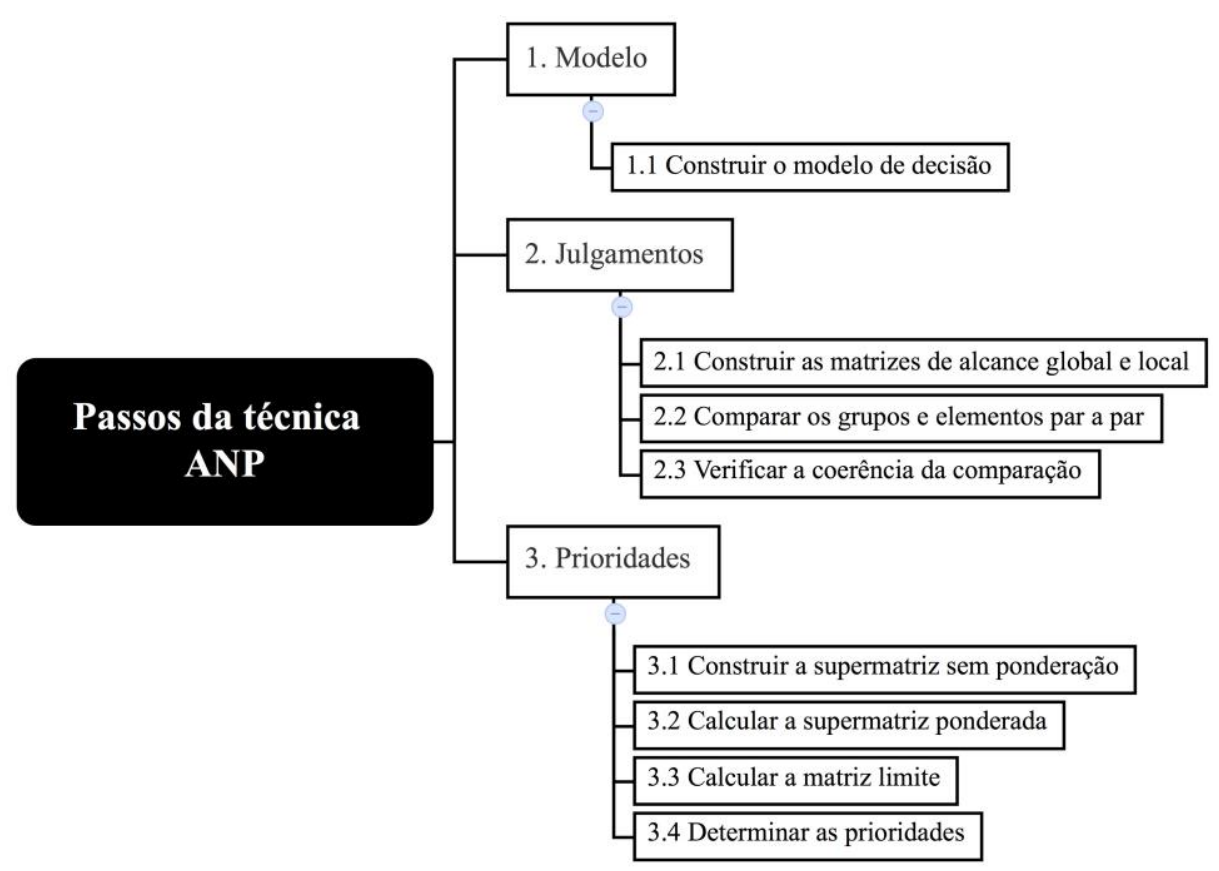

Definido o modelo, no estágio 2 foram efetuados os julgamentos par a par. Para isso é necessário construir as matrizes de alcance (global e local). Para Saaty (1980), a identificação de matrizes de alcance facilita a orientação dos julgamentos. Essas matrizes são binárias e representam a existência de dependência.

Depois, calculou-se o autovetor (vetor de prioridades), normalizou-se o autovetor, criou-se a matriz de peso e calculou-se a supermatriz sem peso. A multiplicação da matriz de peso pela supermatriz sem peso gerou a supermatriz ponderada, que, ao ser elevada à potência até atingir a convergência, gerou uma matriz-limite (matriz estocástica). Finalmente, no estágio 3 tem-se a matriz resultante, que contém as prioridades dos grupos e fatores.

Após as comparações par a par, verificou-se o índice de coerência da comparação. Esse índice mede o nível de inconsistência lógica entre os julgamentos. Por exemplo, se A é mais importante que B e B é mais importante que C, então A é mais importante que C. Qualquer julgamento que contrarie essa lógica gera inconsistência.

A verificação da coerência da comparação para checar se os julgamentos foram consistentes foi feita por uma análise de sensibilidade, que consistiu em variar os valores de alguns elementos e analisar o impacto da variação em outros elementos. O objetivo é verificar se a resposta dada é consistente, além de verificar se os tomadores de decisão foram coerentes nos julgamentos dos critérios. $\mathrm{O}$ cálculo se baseia no número principal de Eigen, que é calculado pela soma do produto de cada elemento do autovetor. Com base no número de Eigen, calcula-se o índice de coerência (IC). IC (índice de coerência $)=($ Número de Eigen $-\mathrm{N}) /(\mathrm{N}-1)$, sendo $\mathrm{N}$ o número de critérios avaliados.

Para verificar se IC é adequado, adotou-se o exposto por Saaty (2005), que recomenda a análise da razão de coerência (RC), calculada pela divisão entre o índice de coerência (IC) e o índice de coerência aleatória (RI). A matriz comparativa normalizada será considerada coerente se o RC ficar abaixo de 10\%; caso contrário, correções nos julgamentos serão necessárias. Saaty (2005) sugeriu números fixos para o índice de coerência aleatória (RI), de acordo com o número de critérios $(\mathrm{N})$, conforme a Tabela 1.

Por fim, no momento 3 discutiu-se o framework comparando-o com o TOE Framework, além da adição das lições advindas da aplicação do framework em uma empresa de construção civil.

\section{Resultados e discussão}

\section{MID Framework de avaliação da complexidade de projetos em portfólios de engenharia civil}

O framework de avaliação da complexidade em portfólio de projetos de engenharia civil foi criado com base nos estudos de Bosch-Rekveldt et al. (2011), Sargut e Mcgrath (2011) e Lukosevicius (2015), de acordo com os passos mostrados na Figura 4. 
Tabela 1 - Índices de coerência aleatória (RI)

\begin{tabular}{c|c|c|c|c|c|c|c|c|c|c}
\hline $\mathrm{N}$ & 1 & 2 & 3 & 4 & 5 & 6 & 7 & 8 & 9 & 10 \\
\hline $\mathrm{RI}$ & 0 & 0 & 0,52 & 0,89 & 1,11 & 1,25 & 1,35 & 1,40 & 1,45 & 1,49 \\
\hline
\end{tabular}

Fonte: Saaty (2005).

Figura 4 - Passos para a criação do framework de avaliação da complexidade

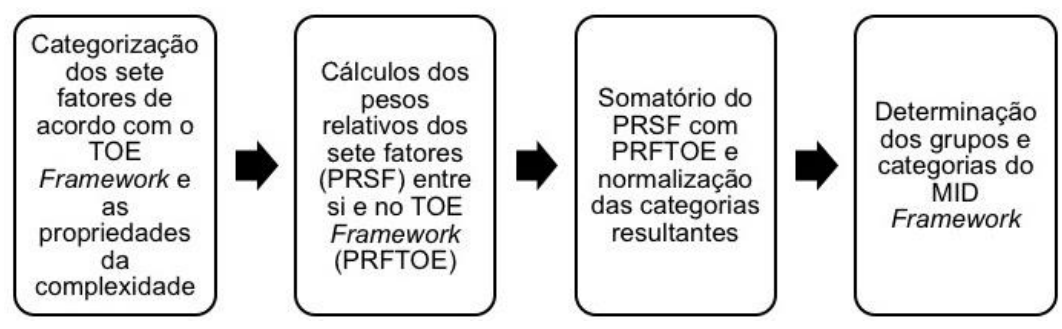

Inicialmente, Sargut e Mcgrath (2011) afirmam que a complexidade possui as propriedades multiplicidade, interdependência e diversidade. A multiplicidade refere-se à quantidade de elementos que potencialmente interagem; a interdependência refere-se à forma como esses elementos estão conectados; e a diversidade refere-se ao nível de heterogeneidade desses elementos (SARGUT; MCGRATH, 2011). Assim, por serem as propriedades da complexidade, as três foram escolhidas para agrupar as variáveis e nomear o framework denominado MID Framework (M de multiplicidade, I de interdependência e D de diversidade). Como apontado anteriormente, Lukosevicius (2015) identificou sete fatores que representam o objeto "projeto complexo" na percepção de 132 profissionais de gerenciamento de projetos da área de engenharia. Esses fatores são a base para a proposição do MID Framework, e o Quadro 2, extraído de Lukosevicius (2015), além de listar os sete fatores, ainda mostra a quantidade de citação que cada fator obteve e o peso relativo.

Em seguida, os sete fatores foram comparados com os fatores do TOE Framework e distribuídos entre os grupos (propriedades da complexidade) a fim de definir os grupos e fatores do MID Framework. Quando surgia uma dúvida na distribuição, recorriase a duas fontes de esclarecimento:

(a) as descrições dos fatores do TOE Framework; e/ou

(b) aos conceitos das propriedades da complexidade.

A resultante dessa comparação pode ser vista no Quadro 2 do Apêndice A.

Durante a comparação percebeu-se que alguns fatores se relacionam a mais de uma propriedade. Para distingui-los, usaram-se os posfixos M para multiplicidade, D para diversidade e I para interdependência. Assim, dessa comparação surgiram os seguintes 15 fatores: Stake_M, Stake_D, Stake_I, Difi_M, Difi_D, Difi_I, Riscos_M, Riscos_D, Tecno_D, Grande_M, Grande_D, Escopo_M, Escopo_D, Multi_I e Longo_M. Porém, de acordo com Lukosevicius (2015), o fator "dificuldade" possui um significado abrangente, que se relaciona com a complexidade de forma geral, não se aplicando a comparação com os elementos do TOE Framework. Assim, os fatores Difi_M, Difi_D e Difi_I possuem o mesmo peso.

O próximo passo foi calcular o peso relativo dos 15 fatores para determinar a importância relativa de cada um. Esse cálculo foi implementado na ordem:

(a) cálculo do peso relativo de cada um dos sete fatores originais (PRSF) entre si;

(b) cálculo do peso relativo dos 15 fatores no TOE Framework (PRFTOE); e

(c) somatório do PRSF com o PRFTOE e normalização dos 15 fatores para determinar seus pesos relativos.

Em primeiro lugar, calculou-se o peso relativo de cada um dos 15 fatores (PRSF) de acordo com a quantidade de citações de cada fator (Quadro 1). Essa operação foi realizada pela normalização da tabela, ou seja, dividiu-se a quantidade de citações do fator pela quantidade total de citações. Por exemplo, o fator stakeholders tem um peso relativo de 19,89\% (37/186). Já o cálculo do peso relativo dos fatores no TOE Framework (PRFTOE) consiste em dividir a quantidade de correspondências do fator no TOE Framework para cada propriedade pela quantidade total de fatores do TOE Framework (50 fatores).

Como mostrado na Tabela 2, por exemplo, o fator stakeholders para a propriedade multiplicidade (denominada Stake_M) foi encontrado três vezes entre os 50 fatores do TOE Framework, então seu peso relativo (PRFTOE) é igual a 0,06 (3/50). Em seguida, somou-se o peso relativo dos sete fatores 
(PRSF) com o peso relativo do fator no TOE Framework (PRFTOE). Com base nessa soma, normalizaram-se os fatores do MID Framework (por exemplo, Stake_M $=0,25892 / 2,73656=$ 0,09462) e determinaram-se seus pesos relativos. Assim, a importância relativa de cada fator do framework foi previamente definida sem a necessidade de comparação par a par.

Finalmente, com base nos passos anteriormente apresentados, sugere-se o MID Framework (multiplicidade, interdependência e diversidade) de avaliação da complexidade do portfólio de projetos na área de engenharia civil (Figura 5).
O MID Framework provê orientações que podem otimizar as comparações par a par, uma vez que são numerosas. Esse número de comparações será reduzido por duas razões:

(a) os grupos multiplicidade, interdependência e diversidade possuem igual preferência entre si, pois se trata de propriedades da complexidade de igual importância. Assim, não existe necessidade de comparar os grupos entre si; e

(b) os 15 fatores do framework podem ser previamente priorizados com base em seus pesos relativos calculados, não havendo a necessidade de compará-los entre si.

Quadro 2 - Peso relativo dos sete fatores

\begin{tabular}{l|c}
\hline \multicolumn{1}{c|}{ Fator } & Quantidade de citações \\
\hline Stakeholders & 37 \\
Dificuldade & 35 \\
Riscos & 25 \\
Tecnologia & 21 \\
Grande & 20 \\
Escopo & 18 \\
Multidisciplinar & 17 \\
Longo & 13 \\
\hline Totais & 186 \\
\hline
\end{tabular}

Fonte: Lukosevicius (2015).

Tabela 2 - Peso relativo dos fatores do MID Framework

\begin{tabular}{l|c|c|c|c}
\hline & $\begin{array}{c}\text { Peso relativo } \\
\text { dos sete fatores } \\
\text { (PRSF) }\end{array}$ & $\begin{array}{c}\text { Peso relativo do } \\
\text { fator no TOE } \\
\text { Framework } \\
\text { (PRFTOE) }\end{array}$ & $\begin{array}{c}\text { Somatório do } \\
\text { PRSF + PRFTOE }\end{array}$ & $\begin{array}{c}\text { Normalização } \\
\text { dos fatores do } \\
\text { MID Framework }\end{array}$ \\
\hline Stake_M & 0,19892 & 0,06000 & 0,25892 & 0,09462 \\
Stake_D & 0,19892 & 0,14000 & 0,33892 & 0,12385 \\
Stake_I & 0,19892 & 0,06000 & 0,25892 & 0,09462 \\
Difi_M,Difi_D, Difi_I & 0,18817 & 0,00000 & 0,18817 & 0,06876 \\
Riscos_M & 0,13441 & 0,06000 & 0,19441 & 0,07104 \\
Riscos_D & 0,13441 & 0,22000 & 0,35441 & 0,12951 \\
Tecno_D & 0,11290 & 0,04000 & 0,15290 & 0,05587 \\
Grande_M & 0,10753 & 0,16000 & 0,26753 & 0,09776 \\
Grande_D & 0,10753 & 0,04000 & 0,14753 & 0,05391 \\
Escopo_M & 0,09677 & 0,04000 & 0,13677 & 0,04998 \\
Escopo_D & 0,09677 & 0,08000 & 0,17677 & 0,06460 \\
Multi_I & 0,09140 & 0,08000 & 0,17140 & 0,06263 \\
Longo_M & 0,06989 & 0,02000 & 0,08989 & 0,03285 \\
\hline
\end{tabular}


Figura 5 - MID Framework de avaliação da complexidade em portfólio de projetos de engenharia civil

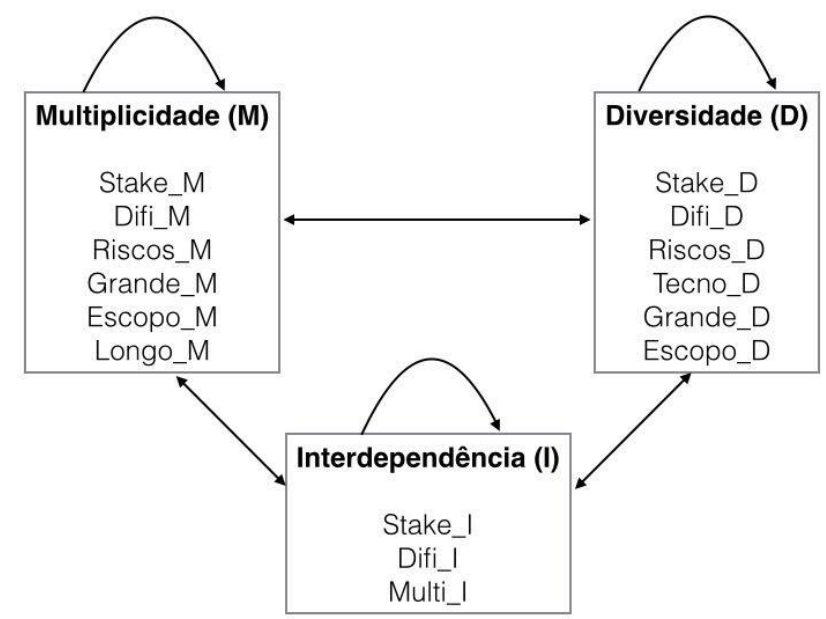

Os significados dos grupos (clusters) e fatores do MID Framework são apresentados a seguir.

(a) Multiplicidade (M): quantidade de elementos potencialmente interagindo entre si:

- Stake_M: número de stakeholders; tamanho da equipe do projeto; horas extras no escritório;

- Difi_M: grau de dificuldade do projeto no que tange à multiplicidade de elementos;

- Escopo_M: número de metas; tamanho do escopo;

- Riscos_M: riscos técnicos; riscos organizacionais; riscos do ambiente;

- Grande_M: número de atividades; tamanho do Capex; tamanho do local; número de locais; número de recursos financeiros; número de nacionalidades diferentes; número de línguas diferentes; e

- Longo_M: duração do projeto.

(b) Interdependência (I): forma como os elementos estão conectados entre si:

- Stake_I: menor cooperação e parceria; dependências de outros stakeholders; baixo suporte interno da organização;

- Difi_I: grau de dificuldade do projeto no que tange à interdependência dos elementos; e

- Multi_I: dependências entre as atividades; interrelacionamento entre técnicas e processos; menor compatibilidade entre os diferentes projetos; número de interfaces entre as diferentes disciplinas.

(c) Diversidade (D): nível de heterogeneidade dos elementos:

- Stake_D: menor disponibilidade de recursos e habilidades; menor experiência com os stakeholders; menor consciência do HSMS (health, safety, security and environment); variedade das perspectivas dos stakeholders; menor influência política e experiência no país; requisição de conteúdo local;

- Difi_D: grau de dificuldade do projeto no que tange à diversidade dos elementos;

- Escopo_D: alinhamento das metas; menor clareza das metas; menor qualidade dos requerimentos; incertezas no escopo;

- Riscos_D: incerteza dos métodos; conflito entre normas e padrões; menor força da orientação do projeto; desconfiança na equipe do projeto; desconfiança no empreiteiro; interferência com locais existentes; menores condições climáticas; local remoto; pressão estratégica interna; instabilidade do ambiente do projeto; nível de competição;

- Tecno_D: tecnologia nova no mundo; experiência com a tecnologia; e

- Grande_D: variedade das atividades; tipos de contrato.

\section{Comparação entre o MID Framework e o TOE Framework}

Inicialmente, cabe diferenciar os objetivos dos dois métodos. O TOE Framework, proposto por BoschRekveldt et al. (2011), visa avaliar a complexidade de grandes projetos de engenharia civil. O MID Framework, proposto neste artigo, visa avaliar a complexidade de qualquer projeto de engenharia em um portfólio de projetos, independentemente da dimensão dele.

Em termos de estrutura, o TOE Framework é formado por 50 elementos, que, segundo os autores, contribuem para a complexidade de um projeto. Esses elementos foram identificados com base na literatura científica e em pesquisa empírica. A 
revisão de literatura sobre os elementos que poderiam contribuir com a complexidade de um projeto de engenharia permitiu identificar 40 elementos. Depois, esses elementos foram comparados com os 49 elementos advindos da pesquisa empírica, que os autores empreenderam por meio de 18 entrevistas a respeito de seis estudos de caso, e a resultante foram os 50 elementos do TOE Framework. Os 50 elementos foram divididos nos grupos de complexidade: técnica, organizacional e ambiental.

Já o MID Framework, estruturalmente, é formado por 15 elementos identificados pela representação social de "projeto complexo" no ponto de vista de 132 profissionais de gerenciamento de projetos de engenharia. Os 15 elementos foram divididos em três grupos (multiplicidade, interdependência e diversidade), que são as propriedades da complexidade, identificadas a partir da revisão de literatura (SARGUT; MCGRATH, 2011). No entanto, a divisão dos 15 elementos entre os grupos teve como referência os 50 elementos do TOE Framework. Portanto, o MID Framework tem a vantagem de ser estruturalmente mais simples que o TOE Framework.

Em termos de aplicação, o TOE Framework pode ser aplicado para avaliar a complexidade total de um projeto e assim melhor entendê-lo e priorizá-lo. Já o MID Framework pode ser aplicado para avaliar a complexidade do projeto e do projeto no portfólio (de cada projeto do portfólio em relação ao mais complexo), permitindo priorização do portfólio de projetos, além de mais uma perspectiva de análise.
Desse modo, a pesquisa sugere que o MID Framework é mais amplo (avalia qualquer tipo de projeto), mais simples (estrutura mais enxuta) e mais diversificado (calcula as complexidades do projeto e do projeto no portfólio) que o TOE Framework para a priorização de portfólio na área de engenharia civil.

A aplicação do MID Framework mostrou que o número de comparações pode aumentar bastante dependendo da quantidade de grupos e fatores do framework. No caso do MID Framework, este número foi minimizado, uma vez que as prioridades relativas entre os grupos e os fatores entre si são previamente definidas pelo framework. Mesmo adotando essas medidas, o tempo para realizar as comparações remanescentes foi considerado demasiado. Assim, o uso de algoritmos como o IPC (Incomplete Pairwise Comparisons) pode otimizar esse quadro.

\section{Aplicação do MID Framework em uma empresa de construção civil}

O MID Framework foi aplicado a uma empresa de construção civil para priorizar seus projetos com base na complexidade deles. A aplicação do framework teve como apoio o software Superdecisions e seguiu os passos apresentados na Figura 6.

A empresa escolhida para a aplicação do MID Framework está presente no mercado brasileiro há mais de 20 anos, tem sede em Brasília, DF, e conta com projetos realizados nos estados de Minas Gerais, Distrito Federal e Goiás. Trata-se da São Francisco Construções e Incorporações.

Figura 6 - Passos para aplicação do MID Framework

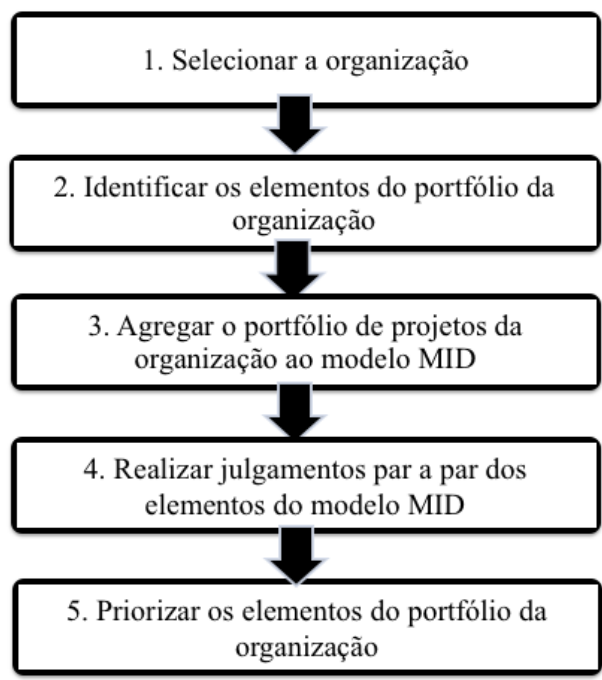


O portfólio da empresa é composto de sete projetos de construção civil do tipo condomínios fechados, loteamentos e edifícios residenciais. Os sete projetos são:

(a) Projeto Terra Park Club Residence: loteamento horizontal fechado com 355 lotes e infraestrutura completa em 280.000 metros quadrados de área total com sistema de segurança, área de lazer, esporte e convivência;

(b) Projeto Edifício Portal do Cerrado: empreendimento de alto padrão, com um apartamento por andar de 250 metros quadrados de área privativa com área de lazer, quatro suítes, área gourmet e condomínio com piscina;

(c) Projeto Condomínio Village Karaíba: condomínio fechado com segurança e área de lazer com 60 casas de quatro e três quartos, e área de lazer completa;

(d) Projeto Ouro Preto Residencial: edifício com apartamentos de três quartos, área de lazer, hall, garagem coberta, sendo apenas quatro apartamentos por andar, com 64 apartamentos de 67 metros de área privativa cada;

(e) Projeto Edifício Terra Mater: empreendimento com apartamentos de três quartos, varanda, garagem e área de lazer, sendo 24 apartamentos de 96 metros de área privativa cada;

(f) Projeto Edifício Sun Phillipe:

empreendimento com apartamentos de dois quartos com suíte, duas vagas na garagem, varanda, salão de festas e guarita de segurança 24 horas, sendo 24 apartamentos de 64 metros de área privativa cada; e

(g) Projeto Edifício Mont Blanc: empreendimento com guarita 24 horas, garagem, varanda e salão de festas, sendo 12 apartamentos de 72 metros de área privativa cada.

Como mostrado anteriormente, o primeiro passo para a aplicação da técnica ANP é definir um modelo de decisão. Dessa forma, a aplicação do MID Framework no portfólio de sete projetos da construtora São Francisco tem início com a modelagem proposta na Figura 7.

O MID Framework traz nativamente as comparações entre os grupos e os fatores. Essa abordagem reduz o número de comparações que os respondentes devem realizar. Esse fato também otimiza o tempo dos respondentes e estimula o emprego do framework em um portfólio com maior número de projetos. Para realizar as comparações dos fatores restantes do framework foi convidado um sócio diretor e fundador da empresa.

Basicamente, as comparações remanescentes consistiram em confrontar os projetos do portfólio em relação aos fatores do framework. Dessa forma, compararam-se os sete projetos do portfólio da construtora São Francisco com os 15 fatores do MID Framework. Como mostrado anteriormente, os julgamentos dos elementos de decisão devem ser feitos dois a dois de acordo com a escala fundamental de Saaty (SAATY, 1980), que vai de 1 a 9.

\section{Figura 7 - MID Framework aplicado ao portfólio de projetos de engenharia da construtora São Francisco}

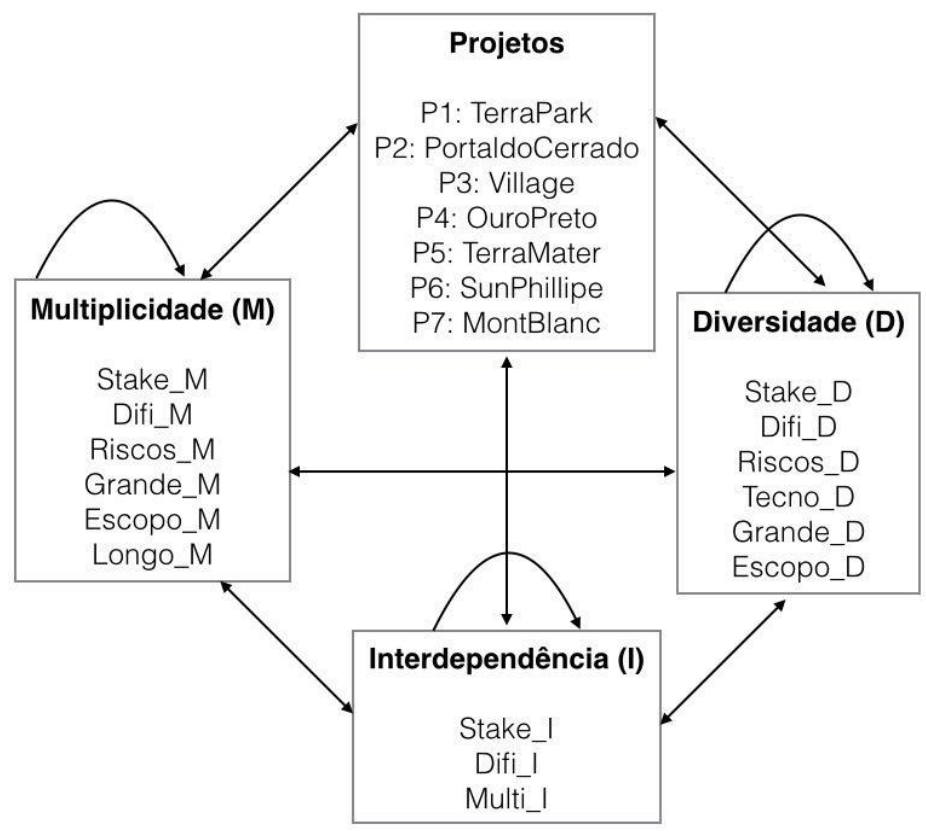


Desse modo, utilizando-se a escala de Saaty, foi solicitado ao respondente que avaliasse dois fatores em relação a determinado projeto, assim como dois projetos em relação a determinado fator. Em termos gerais, estabeleceram-se perguntas do tipo "Qual dos dois fatores apresentados mais influenciou o projeto avaliado?" e "Qual foi o grau dessa influência?".

Portanto, com o apoio do software Superdecisions, foram criadas a supermatriz sem ponderação, a supermatriz ponderada, a matriz-limite e a matriz final, com as prioridades (Tabela 3). Quanto menor o número da prioridade, mais complexo é o projeto dentro do portfólio de projetos da construtora São Francisco.

O projeto P1 - Terra Park foi considerado o mais complexo (prioridade 1), seguido, em ordem decrescente de prioridade, pelos projetos P2 - Portal do Cerrado (prioridade 2), P4 - Ouro Preto (prioridade 3), P5 - Terra Mater (prioridade 4), P6 Sun Phillippe (prioridade 5), P3 - Village (prioridade 6) e P7 - Mont Blanc (prioridade 7).

A complexidade do projeto no portfólio mostra a proporcionalidade das alternativas julgadas (projetos) em relação à alternativa de prioridade 1 (projeto mais complexo do portfólio). Assim, o projeto P1 - Terra Park corresponde a $100 \%$ de complexidade por ser o mais prioritário. O projeto P2 - Portal do Cerrado tem 76,1\% da complexidade do projeto P1, o P4 - Ouro Preto tem 58,09\% da complexidade do projeto P1, P5 - Terra Mater tem $27,12 \%$ da complexidade do projeto P1, P6 - Sun Phillippe tem $21,15 \%$ da complexidade do projeto P1, P3 - Village tem $15,75 \%$ da complexidade do projeto P1, e P7 - Mont Blanc tem 10,13\% da complexidade do projeto P1.

Após as comparações par a par, deve-se verificar o nível de inconsistência lógica entre os julgamentos (análise de sensibilidade). Essa verificação é realizada por meio da razão de coerência. O software Superdecisions permite a checagem automática da razão de coerência. A razão de coerência deve ficar abaixo de $10 \%$ para que o nível de inconsistência seja aceitável. No caso da aplicação do MID Framework no portfólio de projetos da construtora São Francisco, a razão de coerência ficou abaixo de $10 \%$, portanto não será necessário corrigir os julgamentos.

\section{Conclusão}

Em síntese, realizou-se uma pesquisa exploratória com apoio da técnica ANP (Analytic Network Process) para propor um framework de avaliação da complexidade em um portfólio de projetos de engenharia civil. O framework teve como origem os sete fatores (stakeholders, dificuldade, riscos, tecnologia, grande, escopo, multidisciplinar e longo) identificados no trabalho de Lukosevicius (2015), portanto se trata de dados secundários, capturados pelo ponto de vista de 132 profissionais de gerenciamento de projetos da área de engenharia, para representar o objeto "projeto complexo".

Esses fatores foram comparados com os fatores de complexidade TOE Framework para estabelecer os grupos (clusters) e fatores para o MID Framework (multiplicidade, interferência e diversidade) proposto neste estudo. A técnica ANP, de tomada de decisão multicritério, suportada pelo software Superdecisions, foi utilizada para aplicar o MID Framework em um exemplo referente ao portfólio de projetos de uma empresa de construção civil.

Assim, o objetivo de propor um framework para avaliar a complexidade de projetos em portfólios de engenharia civil foi atingido, e a pesquisa sugere que o MID Framework é mais amplo (avalia qualquer tipo de projeto), mais simples (estrutura mais enxuta) e mais diversificado (calcula as complexidades do projeto e do projeto no portfólio) que o TOE Framework para a priorização do portfólio na área de engenharia civil.

Uma implicação acadêmica é a discussão sobre as vantagens e desvantagens do uso de técnicas de apoio à tomada de decisão com múltiplos critérios (como ANP e AHP) para a aplicação de modelos de avaliação de complexidade.

Tabela 3 - Priorização do portfólio da construtora São Francisco de acordo com a complexidade dos projetos

\begin{tabular}{l|c|c|c}
\hline \multicolumn{1}{c|}{ Projetos } & $\begin{array}{c}\text { Complexidade } \\
\text { do projeto }\end{array}$ & $\begin{array}{c}\text { Complexidade do } \\
\text { projeto no portfólio }\end{array}$ & $\begin{array}{c}\text { Prioridade de } \\
\text { complexidade }\end{array}$ \\
\hline P1: Terra Park & 0,0649 & 1,0000 & 1 \\
P2: Portal do Cerrado & 0,0494 & 0,7610 & 2 \\
P4: Ouro Preto & 0,0377 & 0,5809 & 3 \\
P5: Terra Mater & 0,0176 & 0,2712 & 4 \\
P6: Sun Phillippe & 0,0137 & 0,2115 & 5 \\
P3: Village & 0,0102 & 0,1575 & 6 \\
P7: Mont Blanc & 0,0066 & 0,1013 & 7 \\
\hline
\end{tabular}


Já em termos práticos, os gestores de portfólio de projetos na área de engenharia civil podem aplicar o MID Framework para avaliar a complexidade de seus projetos e, assim, priorizar seus portfólios e investimentos de acordo com o critério complexidade.

Porém, são esperadas limitações e fragilidades intrínsecas em todas as técnicas e métodos de pesquisa. Por exemplo, a técnica ANP possui como desvantagem o elevado número de comparações pareadas, fato que pode desestimular seu emprego para um portfólio de projetos com muitos projetos. No caso do MID Framework, minimizou-se esse aspecto negativo predefinindo-se julgamentos de acordo com o peso relativo de cada grupo e dos fatores entre si.

Recomenda-se também que o MID Framework proposto neste artigo seja testado em portfólios de projetos em outras organizações de construção civil, em outras organizações de engenharia diferentes de construção civil e, até mesmo, em outras organizações fora da área de engenharia. Portanto, o MID Framework carece de testes em outros exemplos para ser generalizado.

Além disso, recomenda-se o uso de outras técnicas e instrumentos de pesquisa em substituição, ou em complemento, às técnicas e instrumentos de pesquisa utilizados neste artigo. Por exemplo, seriam bem-vindo estudos com outras técnicas multicritério de tomada de decisão, diferentes da técnica ANP ou, até mesmo, o emprego de algoritmos como o IPC (Incomplete Pairwise Comparisons) para a otimização dos julgamentos par a par. Outra sugestão é estudar se algum fator isolado do MID Framework pode aumentar a complexidade de um único projeto.

Por fim, espera-se que o MID Framework proposto possa auxiliar na priorização de projetos com base no critério complexidade em organizações de construção civil.

\section{Referências}

ARITUA, B.; SMITH, N. J.; BOWER, D. Construction Client Multi-Projects: a complex adaptive systems perspective. International Journal of Project Management, v. 27, n. 1, p. 72-79, 2009.

ASAN, U.; SOYER, A. Identifying Strategic Management Concepts: an analytic network process approach. Computer \& Industrial Engineering, v. 56, p. 600-615, 2009.
BACCARINI, D. The Concept of Project Complexity: a review. International Journal of Project Management, v. 14, n. 4, p. 201 204, 1996.

\section{BANCO NACIONAL DE}

DESENVOLVIMENTO ECONÔMICO E SOCIAL. Fundo de Estruturação de Projetos: BNDES FEP. 2010. Disponível em:

$<$ http://www.bndes.gov.br/SiteBNDES/bndes/bn des_pt/Institucional/Apoio_Financeiro/Apoio_a _estudos_e_pesquisas/BNDES_FEP/index.html >. Acesso em: 6 dez. 2016.

BAR-YAM, Y. Dynamics of Complex Systems : studies in nonlinearity. Bolder: Westview Press, 2003.

BOSCH-REKVELDT, M. et al. Grasping Project Complexity in Large Engineering Projects: the TOE (Technical, Organizational and Environmental) framework. International Journal of Project Management, v. 29, p. 728739, 2011.

BOTTERO, M.; COMINO, E.; RIGGIO, V. Application of the Analytic Hierarchy Process and the Analytic Network Process for the Assessment of Different Wastewater Treatment System. Environmental Modelling \& Software, v. 26, p. 1211-1224, 2011.

CENTRO DE GESTÃO E ESTUDOS ESTRATÉGICOS. Relatório Prospectivo

Setorial: construção civil. Brasília, 2009.

CLARENS, J. Determining the Relationship Between Complexity and Company Profitability. Final year report, Department of industrial engineering. University of Pretoria, 2011. Disponível em:

$<$ http://repository.up.ac.za/handle/2263/17987>. Acesso em: 6 dez. 2016.

COOKE, T. Can Knowledge Sharing Mitigate the Effect of Construction Project Complexity? Construction Innovation, v. 13, n. 1, p. 5-9, 2013.

COOKE-DAVIS, T. et al. We're Not in Kansas Anymore, Toto: mapping the strange landscape of complexity theory. Project Management Journal, v. 38, n. 2, p. 50-61, 2007.

DEPARTAMENTO DA INDÚSTRIA DA CONSTRUÇÃO FIESP. Proposta de Política Industrial Para Construção Civil: edificações. São Paulo: Fiesp, 2008.

DIJKUM, C. From Cybernetics to the Science of Complexity. Kybernets, v. 26, n. 6, p. 725-737, 1997. 
FOSSATI, M.; ROMAN, H. R. Avaliação de Uma Metodologia Para Implantação de Sistemas de Gestão da Qualidade em Empresas de Projetos Para a Construção Civil. Ambiente Construído, Porto Alegre, v. 6, n. 2, p. 45-58, abr./jun. 2006.

GERALDI, J.; MAYLOR, H.; WILLIAMS, T.

Now, Let's Make it Really Complex

(Complicated): a systematic review of the complexities of projects. International Journal of Operations \& Production Management, v. 31, n. 9, p. 966-990, 2011.

GIDADO, K. Project Complexity: the focal point of construction production planning. Construction Management and Economics, v. 14, n. 3, p. 213225, 1996.

GIEZEN, M. Keeping it Simple? A case study into the advantages and disadvantages of reducing complexity in mega project planning. International Journal of Project Management, v. 30, n. 7, p. 781-790, 2012.

GIL, A. C. Como Elaborar Projetos de Pesquisa. 5. ed. São Paulo: Atlas, 2010.

GRANSBERG, D. D. et al. Project Complexity Mapping in Five Dimensions for Complex Transportation Projects. Journal of Managing in Engineering, v. 29, n. 4, p. 316-326, 2012.

HE, Q. et al. Measuring the Complexity of Mega Construction Projects in China: a fuzzy analytic network process analysis.

International Journal of Project

Management, v. 33, p. 549-563, 2015.

IYER, K. C.; CHAPHALKAR, N. B.; JOSHI, G. A. Understanding Time Delay Disputes in Construction Contracts. International Journal of Project Management, v. 26, n. 2, p. 174184, 2008.

KURTZ, C. F.; SNOWDEN, D. J. The New Dynamics of Strategy: sense-making in a complex and complicated world. IBM Systems Journal, v. 42, n. 3, p. 462-482, 2003.

LARSON, E. W.; GOBELI, D. H. Significance of Project Management Structure on Development Success. IEEE Transaction on Engineering Management, v. 36, n. 2, p. 119125,1989

LEBCIR, M.; CHOUDRIE, J. A Dynamic Model of the Effects of Project Complexity on Time to Complete Construction Projects. International Journal of Innovation and Technology Management, v. 2, n. 6, p. 477-483, 2011.
LESSARD, D.; SAKHRANI, V.; MILLER, R. House of Project Complexity: understanding complexity in large infrastructure projects. In: ENGINEERING PROJECT ORGANIZATION CONFERENCE, Colorado, 2013. Proceedings... Colorado, 2013.

LITTLE, T. D. Mean and Covariance Structures (MACS) Analyses of Cross-Cultural Data: practical and theoretical issues. Multivariate Behavioral Research, v. 32, n. 1, p. 53-76, 1997.

LU, Y. et al. Measurement Model of Project Complexity for Large-Scale Projects From Task and Organization Perspective. International Journal of Project Management, v. 33, p. 610 622, 2015.

LUKOSEVICIUS, A. P. Modelo de Avaliação da Complexidade Relativa em Portfólio de Projetos de Engenharia Civil. Niterói, 2015. 185 f. Tese (Doutorado em Engenharia Civil) - Escola de Engenharia, Universidade Federal Fluminense, Niterói, 2015.

MARCH, S. T.; SMITH, G. F. Design and Natural Science Research in Information Technology. Decision Support Systems, v. 15, p. 251-266, 1995.

MARREWIJK, V. A. et al. Managing PublicPrivate Megaprojects: paradoxes, complexity, and project design. International Journal of Project Management, v. 26, p. 591-600, 2008.

MARTINS, M. G.; BARROS, M. M. S. B. A Formação de Parcerias Como Alternativa Para Impulsionar a Inovação na Produção de Edifícios. In: SIMPÓSIO BRASILEIRO DE GESTÃO E ECONOMIA NA CONSTRUÇÃO, 3., São Carlos, 2003. Anais... São Carlos, 2003.

MAYLOR, H.; VIDGEN, R.; CARVER, S. Managerial Complexity in Project-Based Operations: a grounded model and its implications for practice. Project Management Journal, v. 39, p.15-26, 2008.

MELHADO, S. B. Gestão, Cooperação e Integração Para Um Novo Modelo Voltado à Qualidade do Processo de Projeto na Construção de Edifícios. São Paulo, $235 \mathrm{f}$. 2001. Tese (Livre-Docência) - Escola Politécnica, Universidade de São Paulo, São Paulo, 2001.

MOREL, B.; RAMANUJAM, R. Through the Looking Glass of Complexity: the dynamics of organizations as adaptative and evolving systems. Organization Science, v. 10, n. 3, p. 278-293, 1999. 
NEDOPIL, C.; STEGER, U.; AMANN, W. Managing Complexity in Organizations: text and cases. London: Palgrave Macmillan, 2011.

OWENS, J. et al. Defining Complex Project Management of Large US Transportation Projects: a comparative case study analysis. Public Works Manage. Policy, v. 17, n. 2, p. 170-188, 2012.

POUREBRAHIM, S. et al. Analytic Network Process for Criteria Selection in Sustainable Coastal Land Use Planning. Ocean \& Coastal Management, v. 53, p. 544-551, 2010.

PROJECT MANAGEMENT INSTITUTE. Exploring the Complexity of Projects: implications of complexity theory for project management practice. PMI Publishing Division, 2009.

PROJECT MANAGEMENT INSTITUTE.

Navigating complexity: a practice guide. PMI Publishing Division, 2014.

PROJECT MANAGEMENT INSTITUTE.

PMI's Pulse of the Profession In-Depth

Report: navigating complexity. PMI Publishing Division, 2013.

REMINGTON, K.; ZOLIN, R.; TURNER, R. A Model of Project Complexity: distinguishing dimensions of complexity from severity. In: INTERNATIONAL RESEARCH NETWORK OF PROJECT MANAGEMENT CONFERENCE, 9., Berlin, 2009. Proceedings... Berlin, 2009.

RENSBURG, A. C. J. V. Can Complexity Analysis Support Business Performance Insight? South African Journal of Industrial Engineering, v. 23, p. 16-28, 2012.

SAATY, T. L. The Analytic Hierarchy

Process. New York: McGraw Hill, 1980.

SAATY, T. L. Theory and Applications of the Analytic Network Process: decision making with benefits, opportunities, costs, and risks. Pittsburgh: RWS, 2005.

SANTANA, G. Classification of Construction Projects by Scales of Complexity. Project Management, v. 18, n. 2, p. 102-104, 1990.

SARGUT, G.; MCGRATH, R. G. Learning to Live With Complexity. Harvard Business Review, v. 89, n. 9, p. 69-76, 2011.

SAYNISCH, M. Mastering Complexity and Changes in Projects, Economy, and Society Via Project Management Second Order (PM-2).

Project Management Journal, v. 41, n. 5, p. 420, 2010.
SHAFIEI-MONFARED, S.; JENAB, K. A Novel Approach for Complexity Measure Analysis in Design Projects. Journal of Engineering Design, v. 23, n. 3, p. 185-194, 2012.

SHEFFIELD, J.; SANKARAN, S.; HASLETT, T. Systems Thinking: taming complexity in project management. On the Horizon, v. 20, n. 2, p. 126136, 2012.

SINGH, H.; SINGH, A. Principles of Complexity and Chaos Theory in Project Execution: a new approach to management cost engineering. Journal of Cost Engineering, v. 44, n. 12, p. 23-32, 2002.

SINHA, S.; KUMAR, B.; THOMSON, A. Measuring Project Complexity: a project manager's tool. Architectural Engineering and Design Management, v. 2, n. 3, p. 187-202, 2006.

SODERLUND, J. Building Theories of Project Management: past research, questions for the future. International Journal of Project Management, v. 22, n. 3, p. 183-191, 2003.

SOUTO, M. S. M. L. Estudo Comparativo Entre Brasil e Portugal das Práticas Gerenciais em Empresas de Construção Civil Sob a Ótica da Gestão do Conhecimento. Florianópolis, 2003. Tese (Doutorado em Engenharia de Produção) - Programa de PósGraduação em Engenharia de Produção, Universidade Federal de Santa Catarina, Florianópolis, 2003.

SOUZA, E. X. et al. Características das Publicações de Custo Qualidade e Sua Utilização Por Empresas Brasileiras: evidências baseadas em artigos científicos. In: SIMPÓSIO DE ENGENHARIA E PRODUÇÃO, 11., Bauru, 2004. Anais... Bauru, 2004.

VELDE, R. R.; DONK, D. P. V. Understanding Bi-Project Management: engineering complex industrial construction projects. International Journal of Project Management, v. 20, p. 525 533, 2002.

VIDAL, L. A.; MARLE, F. Understanding Project Complexity: implications on project management. Kybernetes, v. 37, n. 8, p. 1094$1110,2008$.

VIDAL, L. A.; MARLE, F.; BOCQUET, J. C. Measuring Project Complexity Using the Analytic Hierarchy Process. International Journal of Project Management, v. 29, n. 6, p. 718-727, 2010.

VIDAL, L. A.; MARLE, F.; BOCQUET, J. C. Using a Delphi Process and the Analytic Hierarchy Process (AHP). Expert Systems with Applications, v. 38, p. 5388-5405, 2011. 
WHITTY, S. J.; MAYLOR, H. And Then Came Complex Project Management (Revised).

International Journal of Project

Management, v. 27, n. 3, p. 304-310, 2009.

WIENDAHL, H. P.; SCHOLTISSEK, P.

Management and Control of Complexity in Manufacturing. Manufacturing Technology, v. 43, n. 2, p. 533-540, 1994

WILLIAMS, T. The Need for New Paradigms for Complex Projects. International Journal of Project Management, v. 17, n. 5, p. 269-273, 1999.
WINTER, M. et al. Directions for Future Research in Project Management: the main findings of a UK government-funded research network.

International Journal of Project Management, v. 24, n. 8 , p. $638-649,2006$.

WOOD, H.; ASHTON, P. The Factors of Project Complexity. TG62. In: CIB WORLD BUILDING CONGRESS, 18., Salford, 2010. Proceedings... Salford, 2010.

XIA, B.; CHAN, A. P. C. Measuring Complexity for Building Projects: a Delphi study. Engineering Construction \& Architectural Management, v. 19, n. 1, p. 7-24, 2012.

XIA, W.; LEE, G. Grasping the Complexity of IS Development Projects. Communications of the ACM, v. 47, n. 5, p. 69-74, 2004.

\section{Apêndice}

Quadro 3 - Uso do TOE Framework como referência para categorizar os fatores nos grupos do MID Framework (Continua...)

\begin{tabular}{|c|c|c|c|c|c|}
\hline $\begin{array}{l}\text { Grupos do } \\
\text { TOE }\end{array}$ & $\begin{array}{l}\text { Subgrupos } \\
\text { do TOE }\end{array}$ & Fatores do TOE & Descrição dos fatores do TOE & $\begin{array}{c}\text { Fatores } \\
\text { identificados por } \\
\text { Lukosevicius } \\
(\mathbf{2 0 1 5 )} \\
\end{array}$ & $\begin{array}{l}\text { Propriedades } \\
\text { da } \\
\text { complexidade }\end{array}$ \\
\hline $\mathrm{T}$ & Metas & Número de metas & $\begin{array}{l}\text { Qual é o número de metas } \\
\text { estratégicas para o projeto? }\end{array}$ & Escopo & Multiplicidade \\
\hline $\mathrm{T}$ & Metas & $\begin{array}{l}\text { Alinhamento das } \\
\text { metas }\end{array}$ & $\begin{array}{l}\text { As metas do projeto estão } \\
\text { alinhadas com a estratégia? }\end{array}$ & Escopo & Diversidade \\
\hline $\mathrm{T}$ & Metas & Clareza das metas & $\begin{array}{l}\text { As metas do projeto são claras } \\
\text { para a equipe do projeto? }\end{array}$ & Escopo & Diversidade \\
\hline $\mathrm{T}$ & Escopo & $\begin{array}{l}\text { Tamanho do } \\
\text { escopo }\end{array}$ & $\begin{array}{l}\text { Qual é o tamanho do projeto } \\
\text { (por exemplo, quantidade de } \\
\text { entregas do projeto)? }\end{array}$ & Escopo & Multiplicidade \\
\hline $\mathrm{T}$ & Escopo & $\begin{array}{l}\text { Incertezas no } \\
\text { escopo }\end{array}$ & Existem incertezas no escopo? & Escopo & Diversidade \\
\hline $\mathrm{T}$ & Escopo & $\begin{array}{l}\text { Qualidade dos } \\
\text { requerimentos }\end{array}$ & $\begin{array}{l}\text { Existem requisitos de qualidade } \\
\text { estritos para as entregas do } \\
\text { projeto? }\end{array}$ & Escopo & Diversidade \\
\hline $\mathrm{T}$ & Atividades & $\begin{array}{l}\text { Número de } \\
\text { atividades }\end{array}$ & $\begin{array}{l}\text { Qual é o número de atividades } \\
\text { envolvidas? }\end{array}$ & Grande & Multiplicidade \\
\hline $\mathrm{T}$ & Atividades & $\begin{array}{l}\text { Variedade das } \\
\text { atividades }\end{array}$ & $\begin{array}{l}\text { O projeto possui atividades } \\
\text { muito variadas? }\end{array}$ & Grande & Diversidade \\
\hline $\mathrm{T}$ & Atividades & $\begin{array}{l}\text { Dependências } \\
\text { entre as atividades }\end{array}$ & $\begin{array}{l}\text { Qual é o número e natureza de } \\
\text { dependência entre as atividades? }\end{array}$ & Multidisciplinar & Interdependência \\
\hline $\mathrm{T}$ & Atividades & $\begin{array}{l}\text { Incerteza nos } \\
\text { métodos }\end{array}$ & $\begin{array}{l}\text { Existem incertezas nos métodos } \\
\text { técnicos a serem aplicados? }\end{array}$ & Risco & Diversidade \\
\hline $\mathrm{T}$ & Atividades & $\begin{array}{l}\text { Inter- } \\
\text { relacionamento } \\
\text { entre técnicas e } \\
\text { processos }\end{array}$ & $\begin{array}{l}\text { Quanto os processos técnicos do } \\
\text { projeto se relacionam com os } \\
\text { processos existentes? }\end{array}$ & Multidisciplinar & Interdependência \\
\hline $\mathrm{T}$ & Atividades & $\begin{array}{l}\text { Conflito entre } \\
\text { normas e padrões }\end{array}$ & $\begin{array}{l}\text { Existe conflito entre os padrões } \\
\text { de design e as normas do país do } \\
\text { projeto? }\end{array}$ & Riscos & Diversidade \\
\hline $\mathrm{T}$ & Experiência & $\begin{array}{l}\text { Tecnologia nova } \\
\text { (no mundo) }\end{array}$ & $\begin{array}{l}\text { O projeto faz uso de novas } \\
\text { tecnologias (novas no mundo e } \\
\text { não somente na empresa)? }\end{array}$ & Tecnologia & Diversidade \\
\hline $\mathrm{T}$ & Experiência & $\begin{array}{l}\text { Experiência com a } \\
\text { tecnologia }\end{array}$ & $\begin{array}{l}\text { As partes interessadas têm } \\
\text { experiência com a tecnologia } \\
\text { adotada no projeto? }\end{array}$ & Tecnologia & Diversidade \\
\hline
\end{tabular}


Quadro 3 - Uso do TOE Framework como referência para categorizar os fatores nos grupos do MID Framework (continuação)

\begin{tabular}{|c|c|c|c|c|c|}
\hline $\begin{array}{l}\text { Grupos do } \\
\text { TOE }\end{array}$ & $\begin{array}{l}\text { Subgrupos } \\
\text { do TOE }\end{array}$ & Fatores do TOE & Descrição dos fatores do TOE & $\begin{array}{c}\text { Fatores } \\
\text { identificados por } \\
\text { Lukosevicius } \\
\text { (2015) }\end{array}$ & $\begin{array}{l}\text { Propriedades } \\
\text { da } \\
\text { complexidade }\end{array}$ \\
\hline $\mathrm{T}$ & Risco & Riscos técnicos & $\begin{array}{l}\text { Você considera o projeto de alto } \\
\text { risco (número, probabilidade } \\
\text { e/ou impacto) em termos de } \\
\text { riscos técnicos? }\end{array}$ & Riscos & Multiplicidade \\
\hline $\mathrm{O}$ & Tamanho & $\begin{array}{l}\text { Duração do } \\
\text { projeto }\end{array}$ & $\begin{array}{l}\text { Qual é a duração planejada para } \\
\text { o projeto? }\end{array}$ & Longo & Multiplicidade \\
\hline $\mathrm{O}$ & Tamanho & $\begin{array}{l}\text { Compatibilidade } \\
\text { dos diferentes } \\
\text { projetos }\end{array}$ & $\begin{array}{l}\text { Você espera problemas de } \\
\text { compatibilidade entre a } \\
\text { metodologia de gerenciamento } \\
\text { de projetos e as ferramentas de } \\
\text { gerenciamento de projetos? }\end{array}$ & Multidisciplinar & Interdependência \\
\hline $\mathrm{O}$ & Tamanho & $\begin{array}{l}\text { Tamanho no } \\
\text { Capex }\end{array}$ & $\begin{array}{l}\text { Qual é o Capex estimado do } \\
\text { projeto? }\end{array}$ & Grande & Multiplicidade \\
\hline $\mathrm{O}$ & Tamanho & $\begin{array}{l}\text { Tamanho em } \\
\text { horas de } \\
\text { engenharia }\end{array}$ & $\begin{array}{l}\text { Qual é a quantidade de horas de } \\
\text { engenharia prevista? }\end{array}$ & Grande & Multiplicidade \\
\hline $\mathrm{O}$ & Tamanho & $\begin{array}{l}\text { Tamanho da } \\
\text { equipe do projeto }\end{array}$ & $\begin{array}{l}\text { Quantas pessoas têm na equipe } \\
\text { do projeto? }\end{array}$ & Stakeholders & Multiplicidade \\
\hline $\mathrm{O}$ & Tamanho & Tamanho do local & $\begin{array}{l}\text { Qual é o tamanho do local de } \\
\text { construção em metros } \\
\text { quadrados? }\end{array}$ & Grande & Multiplicidade \\
\hline $\mathrm{O}$ & Tamanho & Número de locais & $\begin{array}{l}\text { Qual é o número de locais de } \\
\text { construção envolvidos no } \\
\text { projeto, incluindo os locais dos } \\
\text { empreiteiros? }\end{array}$ & Grande & Multiplicidade \\
\hline $\mathrm{O}$ & Recursos & $\begin{array}{l}\text { Força da } \\
\text { orientação do } \\
\text { projeto }\end{array}$ & $\begin{array}{l}\text { O projeto possui forte orientação } \\
\text { (drive), como custo, qualidade } \\
\text { ou cronograma? }\end{array}$ & Riscos & Diversidade \\
\hline $\mathrm{O}$ & Recursos & $\begin{array}{l}\text { Recursos e } \\
\text { habilidades } \\
\text { disponíveis }\end{array}$ & $\begin{array}{l}\text { Os recursos e habilidades } \\
\text { requeridos no projeto estão } \\
\text { disponíveis? }\end{array}$ & Stakeholders & Diversidade \\
\hline $\mathrm{O}$ & Recursos & $\begin{array}{l}\text { Experiência com } \\
\text { as partes } \\
\text { interessadas }\end{array}$ & $\begin{array}{l}\text { Você tem experiência com as } \\
\text { partes envolvidas no projeto? }\end{array}$ & Stakeholders & Diversidade \\
\hline $\mathrm{O}$ & Recursos & $\begin{array}{l}\text { Consciência do } \\
\text { HSSSE }\end{array}$ & $\begin{array}{l}\text { As partes interessadas estão } \\
\text { conscientes da importância do } \\
\text { HSSSE (health, safety, security } \\
\text { and environment)? }\end{array}$ & Stakeholders & Diversidade \\
\hline $\mathrm{O}$ & Recursos & $\begin{array}{l}\text { Interfaces entre } \\
\text { diferentes } \\
\text { disciplinas }\end{array}$ & $\begin{array}{l}\text { Existem interfaces entre as } \\
\text { disciplinas que poderiam causar } \\
\text { problemas de interface? }\end{array}$ & Multidisciplinar & Interdependência \\
\hline $\mathrm{O}$ & Recursos & $\begin{array}{l}\text { Número de } \\
\text { recursos } \\
\text { financeiros }\end{array}$ & $\begin{array}{l}\text { Qual é o número de fontes } \\
\text { financiadoras para o projeto (por } \\
\text { exemplo, investimento próprios, } \\
\text { subsídios)? }\end{array}$ & Grande & Multiplicidade \\
\hline $\mathrm{O}$ & Recursos & Tipos de contrato & $\begin{array}{l}\text { Existem diferentes tipos de } \\
\text { contratos principais? }\end{array}$ & Grande & Diversidade \\
\hline $\mathrm{O}$ & $\begin{array}{l}\text { Equipe do } \\
\text { projeto }\end{array}$ & $\begin{array}{l}\text { Número de } \\
\text { nacionalidades } \\
\text { diferentes }\end{array}$ & $\begin{array}{l}\text { Qual é o número de } \\
\text { nacionalidades diferentes na } \\
\text { equipe de projeto? }\end{array}$ & Grande & Multiplicidade \\
\hline $\mathrm{O}$ & $\begin{array}{l}\text { Equipe do } \\
\text { projeto }\end{array}$ & $\begin{array}{l}\text { Número de } \\
\text { línguas diferentes }\end{array}$ & $\begin{array}{l}\text { Quantas línguas diferentes são } \\
\text { usadas no projeto para a } \\
\text { comunicação? }\end{array}$ & Grande & Multiplicidade \\
\hline $\mathrm{O}$ & $\begin{array}{l}\text { Equipe do } \\
\text { projeto }\end{array}$ & $\begin{array}{l}\text { Cooperação e } \\
\text { parceria }\end{array}$ & $\begin{array}{l}\text { Você coopera com os parceiros } \\
\text { no projeto? }\end{array}$ & Stakeholders & Interdependência \\
\hline $\mathrm{O}$ & $\begin{array}{l}\text { Equipe do } \\
\text { projeto }\end{array}$ & $\begin{array}{l}\text { Horas de transição } \\
\text { no escritório }\end{array}$ & $\begin{array}{l}\text { Quantas horas extras no } \\
\text { escritório demanda o projeto } \\
\text { devido aos diferentes fusos } \\
\text { horários? }\end{array}$ & Stakeholders & Multiplicidade \\
\hline $\mathrm{O}$ & Confiança & $\begin{array}{l}\text { Confiança na } \\
\text { equipe de projeto }\end{array}$ & $\begin{array}{l}\text { Você confia nos membros da } \\
\text { equipe de projeto? }\end{array}$ & Riscos & Diversidade \\
\hline $\mathrm{O}$ & Confiança & $\begin{array}{l}\text { Confiança no } \\
\text { empreiteiro }\end{array}$ & $\begin{array}{l}\text { Você confia no(s) } \\
\text { empreiteiro(s)? }\end{array}$ & Riscos & Diversidade \\
\hline
\end{tabular}


Quadro 3 - Uso do TOE Framework como referência para categorizar os fatores nos grupos do MID Framework (continuação)

\begin{tabular}{|c|c|c|c|c|c|}
\hline $\begin{array}{l}\text { Grupos do } \\
\text { TOE }\end{array}$ & $\begin{array}{l}\text { Subgrupos } \\
\text { do TOE }\end{array}$ & Fatores do TOE & Descrição dos fatores do TOE & $\begin{array}{c}\text { Fatores } \\
\text { identificados por } \\
\text { Lukosevicius } \\
(\mathbf{2 0 1 5}) \\
\end{array}$ & $\begin{array}{l}\text { Propriedades } \\
\text { da } \\
\text { complexidade }\end{array}$ \\
\hline $\mathrm{O}$ & Riscos & $\begin{array}{l}\text { Riscos } \\
\text { organizacionais }\end{array}$ & $\begin{array}{l}\text { Você considera o projeto de alto } \\
\text { risco (número, probabilidade } \\
\text { e/ou impacto) em termos de } \\
\text { riscos organizacionais? }\end{array}$ & Riscos & Multiplicidade \\
\hline $\mathrm{E}$ & Stakeholders & $\begin{array}{l}\text { Número de } \\
\text { stakeholders }\end{array}$ & $\begin{array}{l}\text { Qual é o número de } \\
\text { stakeholders } \\
(\text { ex.: equipe do projeto }=1) \text { ? }\end{array}$ & Stakeholders & Multiplicidade \\
\hline $\mathrm{E}$ & Stakeholders & $\begin{array}{l}\text { Variedade das } \\
\text { perspectivas dos } \\
\text { stakeholders } \\
\end{array}$ & $\begin{array}{l}\text { Stakeholders diferentes têm } \\
\text { expectativas diferentes? }\end{array}$ & Stakeholders & Diversidade \\
\hline $\mathrm{E}$ & Stakeholders & $\begin{array}{l}\text { Dependências de } \\
\text { outros } \\
\text { stakeholders } \\
\end{array}$ & $\begin{array}{l}\text { Qual é o número e natureza das } \\
\text { dependências de outros } \\
\text { stakeholders? }\end{array}$ & Stakeholders & Interdependência \\
\hline $\mathrm{E}$ & Stakeholders & Influência política & $\begin{array}{l}\text { A situação política influencia o } \\
\text { projeto? }\end{array}$ & Stakeholders & Diversidade \\
\hline $\mathrm{E}$ & Stakeholders & $\begin{array}{l}\text { Suporte interno da } \\
\text { organização }\end{array}$ & $\begin{array}{l}\text { Existe suporte gerencial interno } \\
\text { para o projeto? }\end{array}$ & Stakeholders & Interdependência \\
\hline $\mathrm{E}$ & Stakeholders & $\begin{array}{l}\text { Requer conteúdo } \\
\text { local }\end{array}$ & $\begin{array}{l}\text { Qual é a requisição para } \\
\text { conteúdo local? }\end{array}$ & Stakeholders & Diversidade \\
\hline $\mathrm{E}$ & Localização & $\begin{array}{l}\text { Interferência com } \\
\text { locais existentes }\end{array}$ & $\begin{array}{l}\text { Você espera interferências com } \\
\text { o local corrente ou previsto par } \\
\text { ao projeto? }\end{array}$ & Riscos & Diversidade \\
\hline $\mathrm{E}$ & Localização & $\begin{array}{l}\text { Condições } \\
\text { climáticas }\end{array}$ & $\begin{array}{l}\text { Você espera condições de clima } \\
\text { instáveis e/ou adversas?; Elas } \\
\text { podem potencialmente } \\
\text { influenciar o progresso do } \\
\text { projeto? }\end{array}$ & Riscos & Diversidade \\
\hline $\mathrm{E}$ & Localização & Local remoto & Quão remoto é o local? & Riscos & Diversidade \\
\hline \multirow[t]{2}{*}{$\mathrm{E}$} & Localização & $\begin{array}{l}\text { Experiência no } \\
\text { país }\end{array}$ & $\begin{array}{l}\text { As partes interessadas têm } \\
\text { experiência no país do projeto? }\end{array}$ & Stakeholders & Diversidade \\
\hline & $\begin{array}{l}\text { Condições } \\
\text { de mercado }\end{array}$ & $\begin{array}{l}\text { Pressão } \\
\text { estratégica interna }\end{array}$ & $\begin{array}{l}\text { Existe algum pressão de cunho } \\
\text { estratégico vindo do negócio? }\end{array}$ & Riscos & Diversidade \\
\hline $\mathrm{E}$ & $\begin{array}{l}\text { Condições } \\
\text { de mercado }\end{array}$ & $\begin{array}{l}\text { Estabilidade do } \\
\text { ambiente do } \\
\text { projeto }\end{array}$ & $\begin{array}{l}\text { O ambiente do projeto é estável } \\
\text { (por exemplo, taxas de câmbio, } \\
\text { preço da matéria-prima)? }\end{array}$ & Riscos & Diversidade \\
\hline $\mathrm{E}$ & $\begin{array}{l}\text { Condições } \\
\text { de mercado }\end{array}$ & $\begin{array}{l}\text { Nível de } \\
\text { competição }\end{array}$ & $\begin{array}{l}\text { Qual é o nível de competição } \\
\text { (por exemplo, relacionado com } \\
\text { as condições de mercado)? }\end{array}$ & Riscos & Diversidade \\
\hline $\mathrm{E}$ & Risco & $\begin{array}{l}\text { Riscos do } \\
\text { ambiente }\end{array}$ & $\begin{array}{l}\text { Você considera o projeto de alto } \\
\text { risco (número, probabilidade } \\
\text { e/ou impacto) em termos de } \\
\text { riscos para o ambiente? }\end{array}$ & Riscos & Multiplicidade \\
\hline
\end{tabular}

Fonte: adaptado de Lukosevicius (2015). 


\section{Errata}

No artigo "Framework de avaliação da complexidade de projetos em portfólios de engenharia civil", com número de DOI: <http://dx.doi.org/10.1590/s1678-86212017000400200>, publicado no periódico Ambiente Construído, 17(4):323-342.

Na página 323:

Onde se lia (filiação e autoria):

"Alessandra Prudêncio Lukosevicius"

"Carlos Alberto Soares"

Leia-se:

"Alessandro Prudêncio Lukosevicius"

"Carlos Alberto Pereira Soares"

Nas páginas pares:

Onde se lia:

"Soares, C. A."

Leia-se:

"Soares, C. A. P."

Na página 342:

Onde se lia:

"Alessandra Prudêncio Lukosevicius"

"Carlos Alberto Soares"

"Engenharia Civil"

Leia-se:

"Alessandro Prudêncio Lukosevicius"

"Carlos Alberto Pereira Soares"

"Departamento de Engenharia Civil"

Alessandro PrudêncioLukosevicius

Engenharia Civil | Universidade Federal Fluminense | Rua Passo da Pátria, 156, Sala 330, Bloco D | Niterói - RJ - Brasil | CEP 22320-000 | Tel.: (21) 2629-5368 | E-mail: alessanpl@gmail.com

\section{Carlos Alberto Pereira Soares}

Departamento de Engenharia Civil | Universidade Federal Fluminense | E-mail: carlossoares.uff@gmail.com

\section{Luiz Antônio Joia}

Escola Brasileira de Administração Publica e de Empresas | Fundação Getulio Vargas | Praia de Botafogo 190, Sala 526, Botafogo | Rio de Janeiro - RJ - Brasil | CEP 22253-900 | Tel.: (21) 2559-5794 | E-mail: luiz.joia@gmail.com

\section{Revista Ambiente Construído}

Associação Nacional de Tecnologia do Ambiente Construído

Av. Osvaldo Aranha, $99-3^{\circ}$ andar, Centro

Porto Alegre - RS - Brasil

CEP 90035-190

Telefone: +55 (51) 3308-4084

Fax: +55 (51) 3308-4054

www.seer.ufrgs.br/ambienteconstruido

E-mail: ambienteconstruido@ufrgs.br 